\title{
Analysis of the Thematic Progression Patterns in English News Discourse
}

\section{Wang Shuya}

China of Three Gorges University;Institute of foreign languages; Hubei Yichang, China Email: 610028021@qq.com

\author{
Article History \\ Received: 13 July, 2021 \\ Revised: 28 August, 2021 \\ Accepted: 21 September, 2021 \\ Published: 28 September, 2021 \\ Copyright (C) 2021 ARPG \& \\ Author \\ This work is licensed under the \\ Creative Commons Attribution \\ International \\ (क) (i) \\ Commons Attribution License \\ 4.0
}

\begin{abstract}
The theory of theme and rheme and the patterns of thematic progression are not only two important parts of the systemic functional grammar but also an important means of discourse analysis. With thematic structure theory and patterns of thematic progression as the theoretical support, this research makes a combination of theoretical research and discourse analysis. This paper aims to find out the application and characteristics of the theme and rheme structure in English news discourse. After choosing the data from BBC (website:https://www.bbc.com/news/world-asia-china-51403795) reporting on 7th February 2020 with the title of Li Wenliang: Coronavirus Kills Chinese Whistleblower Doctor and giving a detailed analysis by empirical study. Through the analysis of the relationship between theme and rheme in the full text, we find that this text does not only apply a certain thematic progression pattern, but also applies more than one thematic progression pattern. Therefore, we come to the conclusion that thematic progression does exist in this news discourse and shows obvious characteristics and distribution. And also, parallel pattern and continuation pattern are frequently presented in this news discourse.
\end{abstract}

Keywords: Theory of theme and rheme; Thematic progression pattern; News discourse.

\section{Introduction}

The start of 2020 witnessed an outbreak of Covid-19 but its origin still remains a mystery. In the first few months of 2020, the pandemic shook the China as well as the entire world. World economic growth was weak, international economic and trade frictions intensified, and downward pressure on the Chinese economy grew. Struggling against the new coronavirus, numerous ordinary people are fighting day and night to against the death. Although there are nameless heroes died from Covid-19, their recording deeds will be immortal. In the crucial period, many countries kept an close eye on China to follow the trends. Foreign reports on China's epidemic has been presented on a myriad of mainstream platforms. Among them, Li Wenliang, one of the first to raise the alarm about a new coronavirus, died of it on February $7^{\text {th }}$, aged 33, has been remembered by the people. This paper will take Li Wenliang's BBC report as a case study. Although the news background itself is fairly concrete and clear, there is few researchers who use the theory of theme and rheme and the patterns of thematic progression to fully understand and gather the under-structure of this news report text itself.

In Explorations in the Functions of Language, Halliday (1973) proposed that a sentence can be divided into the theme and rheme. The theme is the starting point of the discourse, and the rheme is the core content of the discourse. In the process of language communication, the theme is mostly the known information of the two parties in the communication, while the rheme is the new information which is the unknown information of the recipient that the sender wants to convey. When the theme and subject of the sentence overlap, we named it as unmarked theme. And when the theme and the subject behave differently, we called it as marked theme.

Based on thematic structure theory and thematic progression patterns forwarded by Halliday and Danes, the paper attempts to answer two questions. The one is whether thematic progression exists in Li Wenliang's news discourse and shows obvious characteristics and distribution. And the other one is which pattern of thematic progression is frequently presented most in the discourse. This paper also aims to find out the application of the theme and rheme structure in English news discourse. The significance of Halliday's theme and rheme theory in constructing and understanding English news discourse will be involved as well.

\section{Methodology}

The original source of the news discourse is from the British Broadcasting Corporation (BBC). According to Wikipedia, the BBC is established under a Royal Charter and operates under its Agreement with the Secretary of State for digital, culture, media and sport, which is a British public service broadcaster as well as the world's oldest 
national broadcaster. Therefore, its authority and influence is undoubted known to us all, which is one of the major reason why I choose it. And this reporting news discourse is chosen from BBC (website: https://www.bbc.com/news/world-asia-china-51403795), reporting on 7th February 2020 with the title of Li Wenliang: Coronavirus Kills Chinese Whistleblower Doctor. Because of limited paper space, I only excerpt two representative parts of the news, the story of Li Wenliang and China's reaction towards the death of the hero respectively. The given text in the paper contains 260 words. Taking into account the fact that theme-rheme structure has a strong constructive ability in the process of text generation. Thus, Halliday's theme and rheme theory and thematic progression patterns can be used to analyze news discourse so as to have a clear understanding of the stylistic features and layout of the given text. Moreover, the chosen text have been divide into 13 sentences. Then, the following paper is dedicated to analyzing 13 sentences one after another in a detailed way.

\section{Analytical Framework}

The research on thematic progression have won increasing popularity at home and abroad. There are special connections and changes between the theme and the theme, which constitutes the thematic progression of the text. Dancs (1970) first proposed the concept of thematic progression and three patterns of thematic progression. Chinese linguist Xu Shenghuan (1982) proposed four patterns after synthesizing various domestic and foreign claims. Parallel pattern, continuation pattern, concentrated pattern and crossing pattern are included in the four patterns. This paper will take Xu's four patterns view as the analytical framework to do the following research.

(1) Parallel pattern: taking the theme(T) of the first sentence as the starting point, all subsequent sentences will use the theme of this sentence as the theme and lead different rhemes(R).

$$
\begin{aligned}
& \text { T1-R1 } \\
& \text { T1-R2 } \\
& \text { T1-R3 }
\end{aligned}
$$

(2) Continuation pattern: the rheme or part of the rheme in the first sentence is used as the theme in the second sentence. This theme introduces a new rheme, and the rheme serves as the theme in the next sentence.

$$
\begin{aligned}
& \text { T1-R1 } \\
& \text { T2(R1)-R2 } \\
& \text { T3(R2)-R3 }
\end{aligned}
$$

(3) Concentrated pattern: after the basic themes of the first sentence and the rheme have been made, the second, the third...the sentences start with a new theme, and the different themes of each sentence are concentrated into the same rheme or part of rheme.

$$
\begin{aligned}
& \text { T1-R } \\
& \text { T2-R } \\
& \text { T3-R }
\end{aligned}
$$

(4) Crossing pattern: the theme in the first sentence becomes the rheme in the second sentence, the theme in the second sentence becomes the rheme in the third sentence, and the theme in the third sentence becomes the rheme in the fourth sentence.

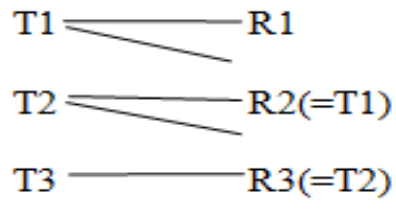

\section{Findings}

In this chapter, the following will take Li Wenliang's report as an example to analyze, expecting to discover the application and pattern of the thematic progression in this news discourse. The definite reporting contents can be seen from Appendix 1 and the complete theme and rheme table is available at Appendix 2.

In this news report, through careful deliberation, the paper below will list the themes of the given sentences one after another (Here T1 stands for the theme of the first sentence and so on):

T1: Dr Li

T2: The 34-year-old

T3: On 30 December

T4: Four days later

T5: In the letter

T6: He

T7: Local authorities

T8: In his Weibo post

T9: $\mathrm{He}$

T10: A wave of anger and grief

T11: The top two trending hashtags

T12: Both hashtags

T13: When the BBC 
Firstly, simple themes take up the absolute majority in themes that appeared in Li Wenliang's report. There are 9 unmarked themes and 4 marked themes. For unmarked theme, take sentence 1, 2, 6, 9 for example, they all refers to Li Wenliang who is the topic of this news, which contributes to the clear logic of the whole passage. For marked theme, take sentence 3, 4 for example, the writer uses "time"(circumstance) as themes. He wants to stress the time sequence that Li Wenliang's story goes.

Secondly, in the first clause, here $\mathrm{T} 1$ serves as the theme to introduce some background information of $\mathrm{Li}$ Wenliang, that is, he works as a doctor and majors in ophthalmology. The rest of the clause serves as the rheme to inform readers what he has done at the very beginning. In the second clause, T2 also refers to Li Wenliang, hoping to give more specific description of the hero aged in 34. Thus, it is clear that the first two sentences share the same theme but in different rheme, which attributes to the parallel pattern. In the third and fourth clause, the reporter takes two adverbials of time as themes-T3 and T4 respectively. On the one hand, it gives people a distinct impression towards the time sequence. On the other hand, it can also unveil the emergence of the epidemic. As for the theme of fifth clause, "In the letter" is one of the rheme part in the fourth clause. Similarly, T8 also partly shares some characteristics of the rheme in the first clause. That is to say, the rheme of the previous sentence is the theme of the latter sentence, which belongs to continuation pattern. This pattern makes the news discourse more coherent. To avoid repetition with previous themes, in the sixth and ninth clauses, the reporter uses "he" refers to Li Wenliang. Therefore, T6 and T9 belong to the parallel pattern as well. When it comes to the description of China's reaction, the reporter uses T10 to intensify the emotion showing in the public. In the eleventh and twelfth clause, T11 and T12 shows the parallel pattern.

Thirdly, analysis of the above thematic progression patterns is shown after:

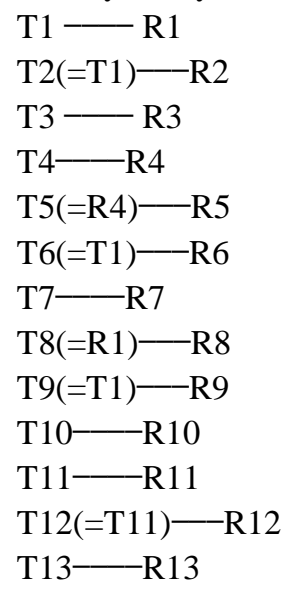

Through the analysis of the relationship between theme and rheme in the full text, this text does not only apply a certain thematic progression pattern, but also applies more than one thematic progression pattern.

\section{Discussion}

The above findings have clearly illustrated the patterns of thematic progression theory applied to Li Wenliang's report. And this chapter follows two parts, the first part is the discussion of the main findings above, the second part is the limitations of the paper and the future research direction.

\subsection{Discussion of the Main Findings}

The paper aims to answer two research questions. From the above data, we can draw the conclusion that the theme progress does indeed exist in the news discourse, and shows obvious characteristics and distribution. We can also find that the parallel pattern and the continuation pattern more often appear in this news discourse, which is consistent with Fries (1983) discussion.

From the T2,T6,T9,T12 analysis of parallel patterns, it can be concluded that parallel pattern has an obvious function as a laying information framework for information to derive around one core content. In the findings part, all the parallel patterns identified in this news discourse have achieved the same function which is significant for news report instead of other genre because the specificity of news reports to provide detailed information about the topic. Due to this function, reading news reports can become more efficient and strategic because all the readers what to know in the discourse can be listed clearly as a parallel pattern.

As for continuation pattern like T5 and T8 above, readers of news reports can follow a smooth logic order when they are getting more information about what they care. With the flow of information, readers can have a macro understanding of the main process of the event. This pattern becomes easier to apply for reporters. Moreover, by changing the previous rheme to the latter theme, the author can better handle the information flow and form a coherent discourse system.

Through analysis, we can find that the thematic progression patterns are indeed present in the news discourse and show obvious characteristics and distribution. Of course, I can not say that the analysis of the above examples can accurately describe the thematic structure and the characteristics of the progression pattern of all news discourses, but it reflects the tendency of a discourse to a certain theme progression pattern. When analyzing a certain type of text, a certain pattern of thematic progression is always presented frequently. It will show dependence on a certain pattern. We can draw conclusions here. As narrative texts, news reports tend to be based on the thematic 
progression pattern with the same theme. The purpose of the news is mainly to make the reader understand what is happening in the outside world and what people are saying about these things. By using the unmarked theme to narrate, the audience or the reader can clearly receive the information that the news itself needs to convey.

Although the article is not long, 13 sentences are involved. The information covered is plentiful. It succinctly summarizes Li Wenliang's story and China's response to the Li Wenliang incident. Its concision and accuracy are determined by the characteristics of the style of the news discourse. The brief and rapid reports of events with a certain social value that have recently occurred at home and abroad are very informative. On the one hand, when reporters do their reporting, new information that may be of interest to readers will naturally be placed behind to make it logical and attractive. On the other hand, it will make readers easy to grasp and accept. In addition, the article basically adopts the unmarked theme structure, which is because the unmarked theme is a more fundamental and relatively high frequency theme type than the marked theme. In other words, the unmarked theme is more reader friendly in most cases.

\subsection{Limitations the Future Research Direction}

The shortcomings of this research lies in the limitations of corpus which is very limited in size. And research methodology is not mature and advanced. It is recommended to enhance the diversity of corpus in the future. Scientifically and sufficient corpus is necessary to keep the research vigorous and practical. The future research could also adopt more sophisticated and inclusive text analysis methods to help promote the new research on the thematic progression patterns.

\section{Conclusion}

In the process of constructing the discourse, the theme and rheme plays a great role. It is significant for us to explore the theme and rheme to master the distribution of information in the text. After analyzing and discussing above, we can come to the conclusion that thematic progression does exist in this news discourse and shows obvious characteristics and distribution. We can also find that is parallel pattern and continuation pattern are frequently presented in this news discourse.

News as a more popular text form, its purpose is to convey to readers the latest events at home and abroad, focusing on the dissemination of information. Therefore, the analysis from the theory of theme and rheme and thematic progression enable to show clear structure and rich content, as well as strong logic and strong readability. In many aspects, there is still room for the improvement in the application of thematic progression in news discourse.

\section{References}

Dancs, F. (1970). On linguistic analysis of text structurce. Folia Linguistics, 1970(4): 102-12.

Fries, P. (1983). On the status of Theme in English: argiunents discourse. Helmut Buske: Hamburg. 1983: $116-52$.

Halliday, M. A. (1973). Explorations in the functions of language. Edward Arnold.

Xu Shenghuan (1982). Theme and Rheme. Oreign Language Teaching and Research. 


\section{Appendix-1. Data}

Website: https://www.bbc.com/news/world-asia-china-51403795

Reporting on $7^{\text {th }}$ February 2020 with the title of Li Wenliang: Coronavirus Kills Chinese Whistleblower Doctor.

$\mathrm{Dr} \mathrm{Li}$, an ophthalmologist, posted his story on Weibo from a hospital bed a month after sending out his initial warning. The 34-year-old had noticed seven cases of a virus that he thought looked like Sars- the virus that led to a global epidemic in 2003. On 30 December he sent a message to fellow doctors in a chat group warning them to wear protective clothing to avoid infection. Four days later he was summoned to the Public Security Bureau where he was told to sign a letter. In the letter he was accused of "making false comments" that had "severely disturbed the social order". He was one of eight people who police said were being investigated for "spreading rumors". Local authorities later apologized to Dr Li. In his Weibo post he describes how on 10 January he started coughing, the next day he had a fever and two days later he was in hospital. He was diagnosed with the coronavirus on 30 January.

A wave of anger and grief flooded Chinese social media site Weibo when news of Dr Li's death broke late on Thursday. The top two trending hashtags on the website were "Wuhan government owes Dr Li Wenliang and apology" and "We want freedom of speech". Both hashtags were quickly censored. When the BBC searched Weibo on Friday morning, hundreds of thousands of comments had already been wiped.

\section{Appendix-2. Theme and Rheme Table}

\begin{tabular}{|c|c|c|c|}
\hline \multirow[t]{2}{*}{$\mathbf{S}$} & \multicolumn{2}{|l|}{ Theme } & \multirow[t]{2}{*}{ Rheme } \\
\hline & Textual & Topical & \\
\hline 1 & & Dr.li & $\begin{array}{l}\text { An ophthalmologist, posted his story on Weibo from a hospital } \\
\text { bed a month after sending out his initial warning. }\end{array}$ \\
\hline 2 & & The 34-year-old & $\begin{array}{l}\text { Had noticed seven cases of a virus that he thought looked like } \\
\text { Sars - the virus that led to a global epidemic in } 2003 \text {. }\end{array}$ \\
\hline 3 & & On 30 December & $\begin{array}{l}\text { He sent a message to fellow doctors in a chat group warning } \\
\text { them to wear protective clothing to avoid infection. }\end{array}$ \\
\hline 4 & & Four days later & $\begin{array}{l}\text { He was summoned to the Public Security Bureau where he was } \\
\text { told to sign a letter. }\end{array}$ \\
\hline 5 & & In the letter & $\begin{array}{l}\text { He was accused of "making false comments" that had "severely } \\
\text { disturbed the social order". }\end{array}$ \\
\hline 6 & & He & $\begin{array}{l}\text { was one of eight people who police said were being investigated } \\
\text { for "spreading rumours" }\end{array}$ \\
\hline 7 & & Local authorities & later apologised to Dr Li. \\
\hline 8 & & $\begin{array}{l}\text { In his Weibo } \\
\text { post }\end{array}$ & $\begin{array}{l}\text { He describes how on } 10 \text { January he started coughing, the next } \\
\text { day he had a fever and two days later he was in hospital. }\end{array}$ \\
\hline 9 & & He & Was diagnosed with the coronavirus on 30 January. \\
\hline $\begin{array}{l}1 \\
0\end{array}$ & & $\begin{array}{l}\text { A wave of anger } \\
\text { and grief }\end{array}$ & $\begin{array}{l}\text { Flooded Chinese social media site Weibo when news of Dr Li's } \\
\text { death broke late on Thursday. }\end{array}$ \\
\hline $\begin{array}{l}1 \\
1\end{array}$ & & $\begin{array}{l}\text { The top two } \\
\text { trending } \\
\text { hashtags }\end{array}$ & $\begin{array}{l}\text { On the website were "Wuhan government owes Dr. Li } \\
\text { Wenliang and apology" and "We want freedom of speech". }\end{array}$ \\
\hline $\begin{array}{l}1 \\
2\end{array}$ & & Both hashtags & Were quickly censored. \\
\hline $\begin{array}{l}1 \\
3\end{array}$ & When & $\begin{array}{l}\text { the BBC } \\
\text { searched Weibo } \\
\text { on Friday } \\
\text { morning, } \\
\text { hundreds of } \\
\text { thousands of } \\
\text { comments }\end{array}$ & Had already been wiped. \\
\hline
\end{tabular}

